\title{
Clinical Application of Tumor Vascular Disrupting Therapy: A Systematic Review and Meta-Analysis
}

\author{
Wen Tsang $(\mathbb{D})^{1,2, *}$ \\ Lu Gan ${ }^{1,2, *}$ \\ Zhikun Zhang $^{1-3, *}$ \\ Tong $\mathrm{Li}^{1,2}$ \\ Yiqun Luo ${ }^{1,2}$ \\ Liping Zhong ${ }^{1,2}$ \\ Yong Huang ${ }^{1,2}$
}

'National Center for International Research of Bio-Targeting Theranostics, Guangxi Key Laboratory of Bio-Targeting Theranostics, Guangxi Medical University, Nanning, Guangxi, 53002I, People's Republic of China; ${ }^{2}$ Collaborative Innovation Center for Targeting Tumor Diagnosis and Therapy, Guangxi Medical University, Nanning,, Guangxi, 53002I, People's Republic of China; ${ }^{3}$ Mental Health Center, the Second Affiliated Hospital of Guangxi Medical University, Nanning, Guangxi, People's Republic of China

*These authors contributed equally to this work

\begin{abstract}
Purpose: The occurrence, progression, invasion and metastasis of tumors depend on a tumor vascular network. Vascular disrupting agents (VDAs) are a new class of drugs targeting the tumor vasculature, by blocking the existing tumor blood vessels. However, there is no clear consensus on the clinical efficacy of tumor vascular disrupting therapy. In this study, we performed the first systematic review and meta-analysis of published clinical trials focused on tumor vascular disrupting therapies.
\end{abstract}

Materials and Methods: We searched PubMed, EMBASE, and the Cochrane Library to identify clinical trials that used VDAs to treat tumors. After literature screening and data extraction, according to inclusion and exclusion labels, meta-analysis was performed using RevMan5.3 software.

Results: In this meta-analysis, we included 2659 patients from eight randomized controlled trials involving non-small-cell lung cancer, prostate, epithelial ovarian, fallopian tube, and primary peritoneal carcinoma. Compared with the control arm, the experimental arm exhibited an effective improvement of 0.5-year and 1-year survival, as well as the 6-month progression-free survival rate. There was no significant difference between patients in the experimental compared to the control arm with respect to objective response and disease control rates, and 12-month progression-free survival.

Conclusion: Vascular disrupting therapy can effectively prolong the survival of cancer patients. However, for indicators of short-term efficacy, such as objective response rate and disease control rate, there is still a lack of high-quality, large-scale clinical trial data to confirm the effectiveness of VDAs.

Keywords: tumor, vascular targeted therapy, vascular disrupting agents, meta-analysis

\section{Introduction}

As the aging population has expanded, the burden of cancer morbidity and mortality has increased rapidly worldwide. According to World Health Organization estimates in 2019, cancer is the first or second leading cause of death among people under the age of 70 in 112 of 183 countries. ${ }^{1}$ Although the existing first-line cancer treatment methods, such as surgery, chemotherapy, and radiotherapy, have achieved remarkable positive results, there are still limitations to their efficacy. ${ }^{2}$ Furthermore, despite continuous innovation in the development of drugs and treatments for tumors, the 5-year survival rates of various cancers (including pancreatic, liver, and lung cancer) have remained low, indicating the need for more effective treatments. ${ }^{3}$ Tumor targeted therapy uses targeted technology to accurately deliver drugs to the tumor area at the cellular and molecular level. Based on the use of different targeting sites, tumor targeted therapy can be divided into two categories, namely tumor cell targeted 
therapy and tumor vascular targeted therapy. ${ }^{4,5}$ The latter technique takes advantage of the abnormal structure and function of tumor vessels. Anti-angiogenesis therapy involves inhibiting the development of neovascularization, while vascular disrupting therapy is aimed at the destruction of the established tumor vascular system. ${ }^{6}$

The drugs used in tumor vascular disrupting therapy are called vascular disrupting agents (VDAs). VDAs can selectively target tumor vessels via multiple pathways to inhibit blood flow within tumors, leading to extensive secondary necrosis within tumors while leaving normal tissues relatively intact. ${ }^{7}$ Based on their mechanisms of action, VDAs can be divided into two categories: liganddirected VDAs and small molecular VDAs. ${ }^{8,9}$ Liganddirected VDAs target up-regulated molecules in tumor vascular endothelial cells and deliver toxins, coagulants, or pro-apoptotic factors to tumor-related vessels via targeted ligands such as antibodies, peptides, or growth factors. However, most ligand-directed VDAs, except tTF-NGR, have not yet entered the clinical research stage. ${ }^{10}$ Small molecular VDAs cause tumor vascular dysfunction by taking advantage of the pathophysiological differences between tumor-related vessels and normal blood vessels. Small molecular VDAs can be divided into three categories. The first category comprises flavonoids, which exert anti-vascular effects by inducing the production of local cytokines. ${ }^{11}$ The second category covers $\mathrm{N}$-cadherin antagonists, which act by preventing cadherins from coagulating with each other in the tumor vascular system. ${ }^{12}$ The last category consists of tubulinbinding agents, which work by inducing microtubule depolymerization and the separation of actin and tubulin. ${ }^{13}$

In this study, we performed the first systematic review and meta-analysis of clinical data on tumor vascular disrupting therapy in the existing literature, determined the role of VDAs in tumor treatment, and provide guidance for further research and clinical applications.

\section{Materials and Methods}

\section{Acquisition of Relevant Studies}

Our systematic review and meta-analysis were prepared based on the Preferred Reporting Items for Systematic Reviews and Meta-Analyses (PRISMA) guidelines. The protocol was published on the International Platform of Registered Systematic Review and Meta-analysis Protocols (INPLASY; registration number: INPLASY202140111). ${ }^{14}$
In order to obtain relevant studies, we searched the PubMed, EMBASE, and Cochrane Library databases for articles ranging from the earliest publications included in the database up until 10 August 2021. For studies drawn from PubMed, we used the following medical subject headings (MeSH) and non-MeSH terms for the selection of relevant patients: "Neoplasms" or "Neoplasia" or "Neoplasm" or "Tumor" or "Cancer" or "Malignancy" or "Benign". With regards to selecting relevant interventions, the following terms were used: "Anti-vascular agent" or "Vascular disrupting agent" or "Tubulin-binding agent" or "Flavonoid" or "N-cadherin". For the selection of relevant types of studies, the following MeSH and non-MeSH terms were used: "Clinical Trial [Publication Type]" or "Clinical trial". Articles that did not have English versions were excluded.

\section{Eligibility Criteria}

All possible publications were screened independently by two reviewers. Duplicate records were excluded. Reviews, conference abstracts, animal studies, mechanism studies, and Phase I trials were also excluded. All publications that did not involve tumors, VDAs, and clinical trials were deleted. We deleted trials involving single-arm trials, nonrandomized control trials, treatments that were not eligible, and trials that did not have sufficient available data. Two reviewers independently reviewed the full text manuscripts of the qualified trials, used standardized Excel tables to extract data, and cross-validated the information. If there was a disagreement, a third reviewer was recruited to help resolve the problem.

\section{Data Extraction}

We collected the following data from the published trials: first author, publication year, study design, randomization method, basic characteristics of patients, tumor type, experimental arm, and control arm. In cases where the information was incomplete, we contacted the authors of the article in order to obtain the missing data.

The main clinical evaluation indexes included objective response rate (ORR), disease control rate (DCR), 6-month progression-free survival (PFS) rate, 12-month PFS rate, 0.5-year survival rate, and 1-year survival rate.

In this meta-analysis, the experimental arm included patients who received VDA alone or VDA combined with traditional therapy, while the control arm included patients who received traditional therapy alone, or placebo combined with traditional therapy. 


\section{Quality Assessment and Publication Bias}

The Cochrane System Evaluation Manual Intervention was used to evaluate the quality of the randomized control clinical trials. ${ }^{15}$ Funnel plots were constructed to assess the risk of publication bias. However, if fewer than 10 articles were assessed, there was no need to determine publication bias.

\section{Statistical Analysis}

The meta-analysis was performed using RevMan software, version 5.3 (The Cochrane Collaboration, London, UK). We calculated the odds ratio (OR) and 95\% confidence interval $(\mathrm{CI})$ of binary variables. The heterogeneity of the included data was determined by chi-square test and Higgins' $\mathrm{I}^{2}$ statistics test. ${ }^{16}$ If $P>0.10$ and $I^{2}<50 \%$ indicated no heterogeneity, a fixed-effects model was used for statistical assessment. If $P \leq 0.10$ or $I^{2} \geq 50 \%$ indicated substantial heterogeneity, a random-effects model was used for statistical assessment. The overall effect of the meta-analysis was Z-tested, with $P<0.05$ considered to be a significant difference, $P<0.01$ represented a high significant difference, and $P>0.05$ was not significant. In sensitivity analysis, single articles were excluded and the meta-analysis was repeated to evaluate the comprehensive effects.

\section{Results}

\section{Search results}

In our search of the literature, we found 492 possible relevant publications: 150 of them were deposited in Pubmed, 82 were from EMBASE, and 260 were from the Cochrane Library. Figure 1 presents the processes and reasons for study selection. Among the initial publications, 84 duplicates were excluded. After reading the title, abstract, and full text, 8 randomized controlled trials were included in the meta-analysis. ${ }^{17-24}$
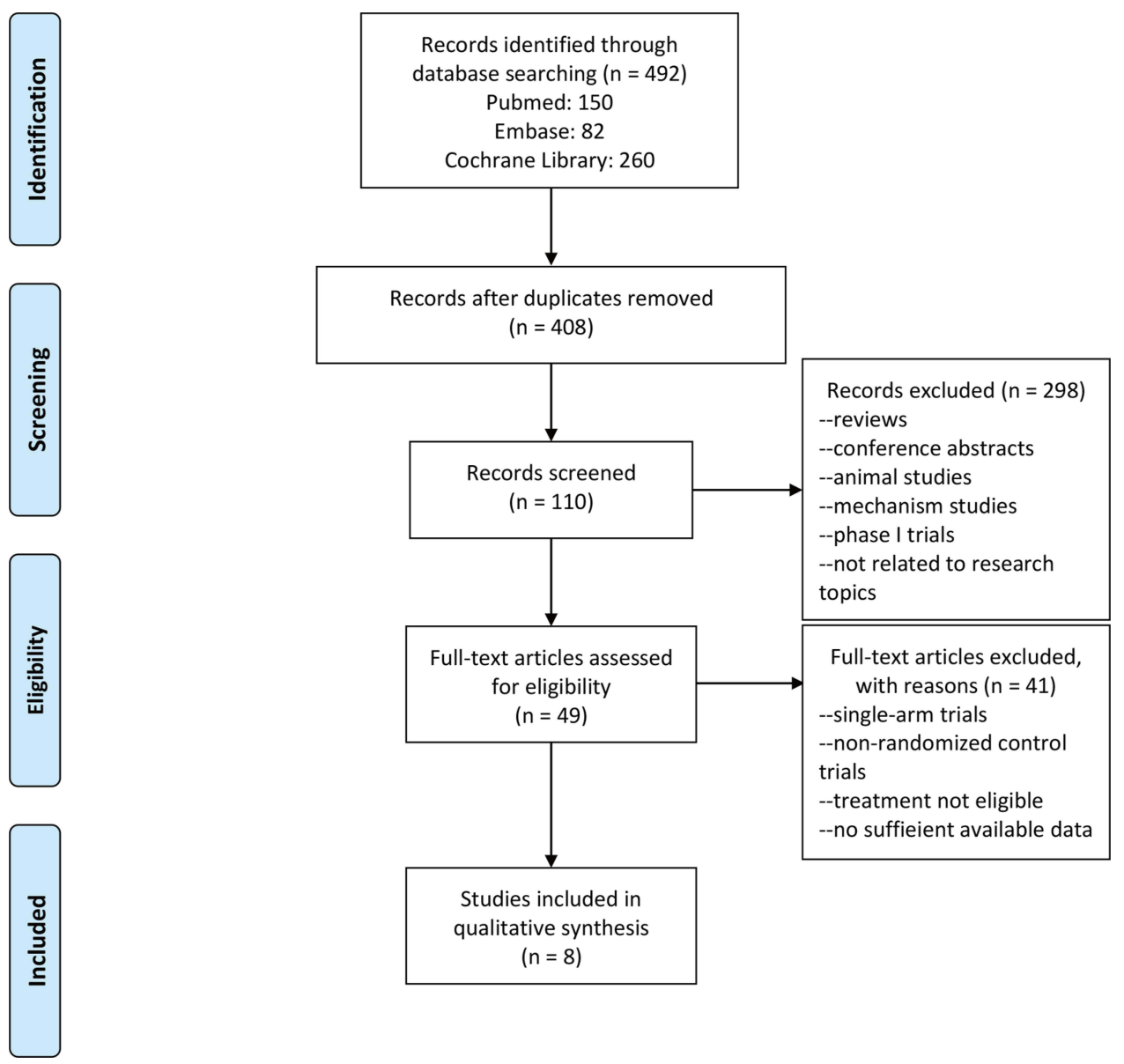

Figure I PRISMA flow diagram of included studies.

Notes: PRISMA figure adapted from Moher D, Liberati A, Altman D, Tetzlaff J, et al. The PRISMA statement for reporting systematic reviews and meta-analyses of studies that evaluate health care interventions: explanation and elaboration. Journal of clinical epidemiology. 2009;62(I0). Creative Commons. ${ }^{14}$ 
Table I Basic Characteristics of the 8 Trials Included in the Meta-Analysis

\begin{tabular}{|c|c|c|c|c|c|c|c|}
\hline \multirow[t]{2}{*}{ Study } & \multirow[t]{2}{*}{ Year } & \multirow[t]{2}{*}{ Phase } & \multirow[t]{2}{*}{ Cancer Type } & \multirow{2}{*}{$\begin{array}{c}\text { No. of } \\
\text { Patients }\end{array}$} & \multirow{2}{*}{$\begin{array}{l}\text { Mean } \\
\text { Age, } \\
\text { Year }\end{array}$} & \multicolumn{2}{|c|}{ Treatment } \\
\hline & & & & & & Experimental Arm & Control Arm \\
\hline Morgan et al ${ }^{17}$ & 2020 & ॥ & $\begin{array}{l}\text { Epithelial ovarian, fallopian tube } \\
\text { or primary peritoneal carcinoma }\end{array}$ & 21 & 58.5 & $\begin{array}{l}\text { Pazopanib + } \\
\text { fosbretabulin }\end{array}$ & Pazopanib \\
\hline Garon et al ${ }^{18}$ & 2016 & II & Non-small-cell lung cancer & 63 & 62.2 & $\begin{array}{l}\text { CA4P + carboplatin + } \\
\text { paclitaxel }+ \\
\text { bevacizumab }\end{array}$ & $\begin{array}{l}\text { Carboplatin + } \\
\text { paclitaxel + } \\
\text { bevacizumab }\end{array}$ \\
\hline Monk et al ${ }^{19}$ & 2016 & II & $\begin{array}{l}\text { Epithelial ovarian, fallopian tube, } \\
\text { or primary peritoneal carcinoma }\end{array}$ & 107 & $\begin{array}{l}\text { No } \\
\text { report }\end{array}$ & $\begin{array}{l}\text { Bevacizumab }+ \\
\text { fosbretabulin }\end{array}$ & Bevacizumab \\
\hline Von Pawel et al ${ }^{20}$ & 2014 & ॥ & Non-small-cell lung cancer & 176 & 61.5 & $\begin{array}{l}\text { Ombrabulin + } \\
\text { chemotherapy }\end{array}$ & $\begin{array}{l}\text { Placebo }+ \\
\text { chemotherapy }\end{array}$ \\
\hline Rudin et $\mathrm{al}^{2 \mathrm{I}}$ & 2011 & II & Non-small-cell lung cancer & 165 & 62.3 & ABT-75I + pemetrexed & $\begin{array}{l}\text { Placebo }+ \\
\text { pemetrexed }\end{array}$ \\
\hline Lara et $\mathrm{al}^{22}$ & 2011 & III & Non-small-cell lung cancer & 1299 & 61.5 & $\begin{array}{l}\text { ASA404 + carboplatin/ } \\
\text { paclitaxel }\end{array}$ & $\begin{array}{l}\text { Placebo }+ \\
\text { carboplatin/ } \\
\text { paclitaxel }\end{array}$ \\
\hline De Bono et $\mathrm{al}^{23}$ & 2010 & III & Prostate cancer & 755 & 67.5 & Cabazitaxel & Mitoxantrone \\
\hline McKeage et $\mathrm{al}^{24}$ & 2008 & II & Non-small-cell lung cancer & 73 & 23.5 & $\begin{array}{l}\text { ASA404 + carboplatin/ } \\
\text { paclitaxel }\end{array}$ & $\begin{array}{l}\text { Carboplatin/ } \\
\text { paclitaxel }\end{array}$ \\
\hline
\end{tabular}

\section{Study Characteristics}

Table 1 lists the basic characteristics of the included studies. This meta-analysis included 2659 patients (1332 in the experimental arms and 1327 in the control arms) from 8 randomized controlled trials.

\section{Risk of Bias Assessment}

All of the included trials used a randomized design, and one trial provided details of the random sequence generation method. With regards to the blinding method, 3 trials were double-blinded (in terms of subjects and clinicians or therapeutic use) and 5 trials were designed to be openlabel. With the exception of 2 trials that were not able to determine the efficacy and safety of the drug, the other 6 trials reported pre-specified results. The detailed results of the evaluation are shown in Figure 2A and B.

\section{Efficacy Evaluation \\ Objective Response Rate}

Eight studies reported a difference in the ORR between the experimental arm and the control arm. ${ }^{17-24}$ Moderate heterogeneity $\left(P=0.05, I^{2}=50 \%\right)$ was present, and a randomeffects model was used for statistical analysis (Figure 3A).
Using sensitivity analysis, we found that the heterogeneity changed after the exclusion of articles by de Bono et al $\left(P=0.49, I^{2}=0 \%\right){ }^{23}$ These results indicated that this article was the source of the heterogeneity, and we therefore excluded this article and re-analyzed the data. A final total of 7 studies were included in this study and a fixed-effects model was adopted. The meta-analysis revealed no significant difference in ORR between the experimental arm and the control arm (OR 1.10, 95\% CI 0.89-1.37, $P=0.37$; Figure 3B).

\section{Disease Control Rate}

Four studies reported a difference in the DCR between the experimental arm and the control arm, with no heterogeneity $\left(P=0.87, I^{2}=0 \%\right)$, and thus a fixed-effects model was used for statistical analysis. ${ }^{19,20,22,24}$ The metaanalysis showed no significant difference in DCR between the experimental arm and the control arm (OR 1.02, 95\% CI $0.83-1.26, P=0.86$; Figure 4 ).

\section{Progression-Free Survival at 6 Months}

Four studies reported a difference in the 6-month PFS rate between the experimental arm and the control arm, and there was mild but acceptable heterogeneity $\left(P=0.15, I^{2}=\right.$ $44 \%){ }^{17,18,20,23}$ The fixed-effects model was used for 
A

Random sequence generation (selection bias)

Allocation concealment (selection bias)

Blinding of participants and personnel (performance bias)

Blinding of outcome assessment (detection bias)

Incomplete outcome data (attrition bias)

Selective reporting (reporting bias)

Other bias
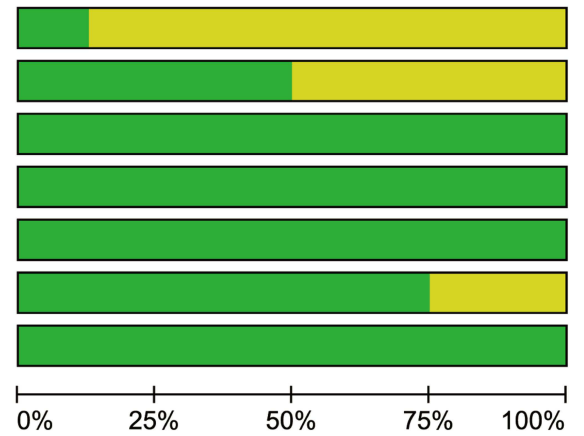

Low risk of bias Unclear risk of bias

High risk of bias

B

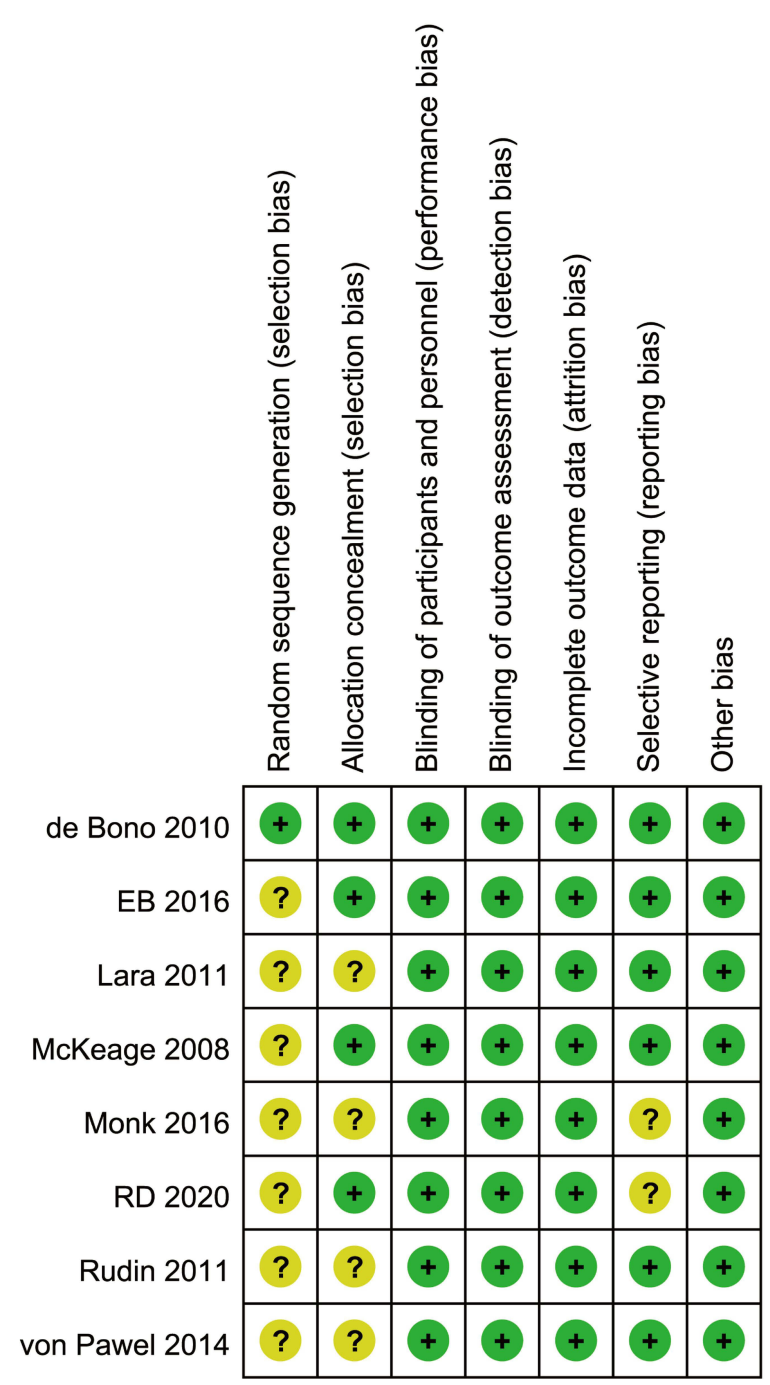

Figure 2 Risk of bias graph (A) and risk of bias summary (B) for all included trials.

statistical analysis. Meta-analysis showed a high significant difference in the 6-month PFS rate between the experimental arm and the control arm (OR 1.60, 95\% CI $1.18-2.16, P=0.002$; Figure 5).

\section{Progression-Free Survival at 12 Months}

Five studies reported a difference in the 12-month PFS rate between the experimental arm and the control arm, without heterogeneity $\left(P=0.51, I^{2}=0 \%\right) .{ }^{17-19,22,23}$ The fixed- 


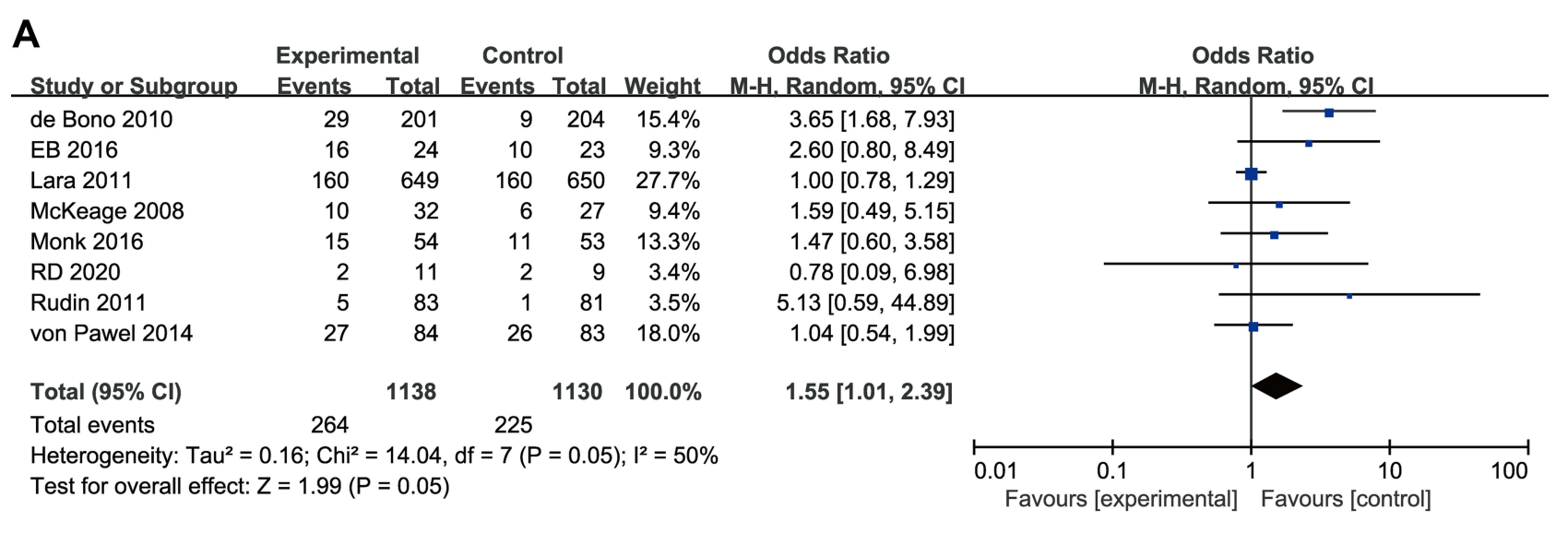

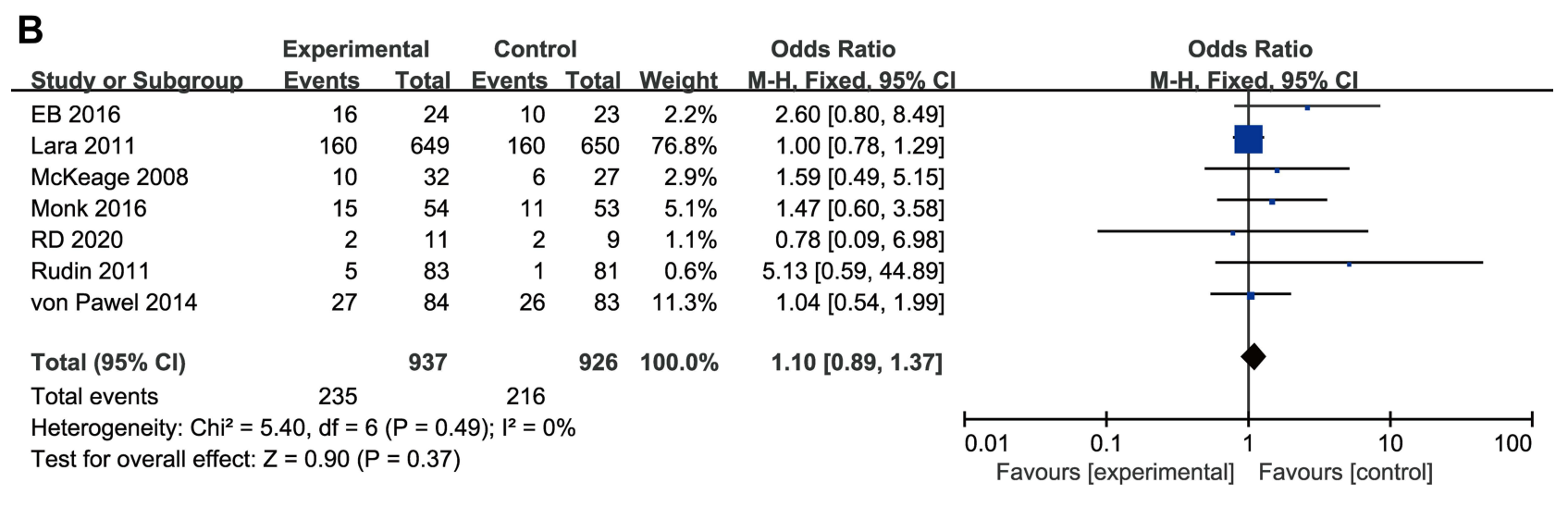

Figure 3 Forest plot diagram of the objective response rate. (A) Forest plot diagram analysed using random-effects model. (B) Forest plot diagram analysed using fixed-effects model.

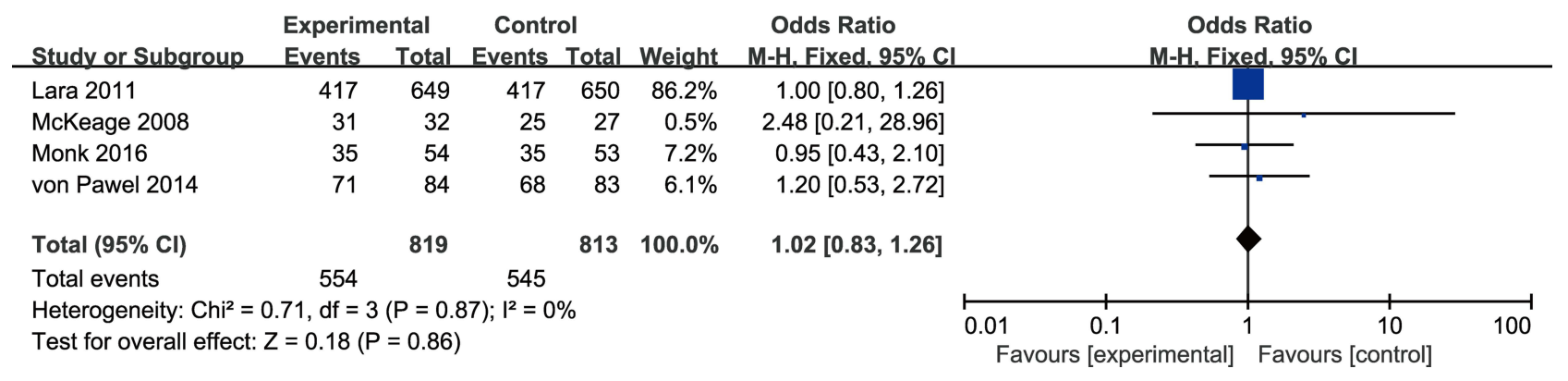

Figure 4 Forest plot diagram of the disease control rate.

\begin{tabular}{|c|c|c|c|c|c|c|c|c|c|}
\hline Study or Subgroup & $\begin{array}{l}\text { Experim } \\
\text { Events }\end{array}$ & $\begin{array}{l}\text { ntal } \\
\text { Total }\end{array}$ & $\begin{array}{l}\text { Contrc } \\
\text { Events }\end{array}$ & $\begin{array}{l}\text { ol } \\
\text { Total }\end{array}$ & Weight & $\begin{array}{l}\text { Odds Ratio } \\
\text { M-H.Fixed. } 95 \% \mathrm{Cl}\end{array}$ & $\begin{array}{r}\text { Odds } \\
\text { M-H.Fixe }\end{array}$ & $\begin{array}{l}\text { Ratio } \\
\text { ed. } 95 \% \mathrm{Cl}\end{array}$ & \\
\hline de Bono 2010 & 90 & 378 & 52 & 377 & $58.4 \%$ & $1.95[1.34,2.85]$ & & - & \\
\hline EB 2016 & 18 & 32 & 18 & 31 & $11.8 \%$ & $0.93[0.34,2.52]$ & & & \\
\hline RD 2020 & 7 & 11 & 3 & 10 & $1.7 \%$ & $4.08[0.66,25.38]$ & & & \\
\hline von Pawel 2014 & 28 & 88 & 28 & 88 & $28.1 \%$ & $1.00[0.53,1.89]$ & & & \\
\hline Total $(95 \% \mathrm{Cl})$ & & 509 & & 506 & $100.0 \%$ & $1.60[1.18,2.16]$ & & & \\
\hline Total events & 143 & & 101 & & & & & & \\
\hline \multicolumn{7}{|c|}{$\begin{array}{l}\text { Heterogeneity: } \text { Chi }^{2}=5.34, d f=3(P=0.15) ; I^{2}=44 \% \\
\text { Test for overall effect: } Z=3.07(P=0.002)\end{array}$} & $\begin{array}{ll}0.01 & 0.1 \\
\text { Favours [experimental] }\end{array}$ & $\begin{array}{l}1 \\
\text { Favours [control] }\end{array}$ & 100 \\
\hline
\end{tabular}

Figure 5 Forest plot diagram of the 6-month progression-free survival rate. 


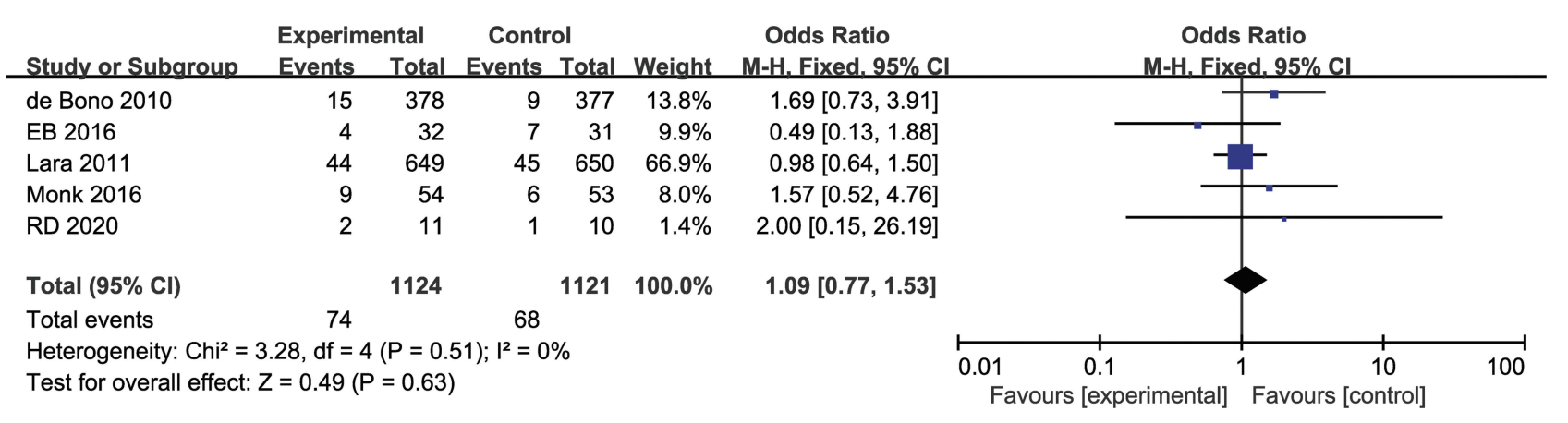

Figure 6 Forest plot diagram of the 12-month progression-free survival rate.

effects model was used for statistical analysis. However, meta-analysis showed no significant difference in the 12 month PFS rate between the experimental and the control arms (OR 1.09, 95\% CI 0.77-1.53, $P=0.63$; Figure 6).

\section{Survival Rate at 0.5 Years}

Four studies reported a difference in the 0.5-year survival rate between the experimental arm and the control arm, with moderate heterogeneity $(P=0.06$, $\left.I^{2}=59 \%\right){ }^{17,18,20,23}$ The random-effects model was used for statistical analysis (Figure 7A). Using sensitivity analysis, we found that the heterogeneity changed after the exclusion of articles by Joachim von Pawel et al $\left(P=0.32, I^{2}=11 \%\right),{ }^{20}$ suggesting this article was the source of heterogeneity. After exclusion of this article and re-analysis, we included 3 studies in this evaluation and adopted a fixed-effects model for statistical analysis. Meta-analysis showed that there was a high significant difference in the 0.5year survival rate between the experimental arm and the control arm (OR 1.63, 95\% CI 1.23-2.15, $P=0.0006$; Figure 7B).

\section{Survival Rate at I Year}

Six studies reported a difference in the 1-year survival rate between the experimental and control arms, without heterogeneity $\left(P=0.54, I^{2}=0 \%\right) .{ }^{17-20,23,24}$ The fixed-effects model was thus used for statistical analysis. Metaanalysis showed that there was a high significant difference in the 1year survival rate between the experimental arm and the control arm (OR 1.43, 95\% CI 1.11-1.84, $P=0.005$; Figure 8).

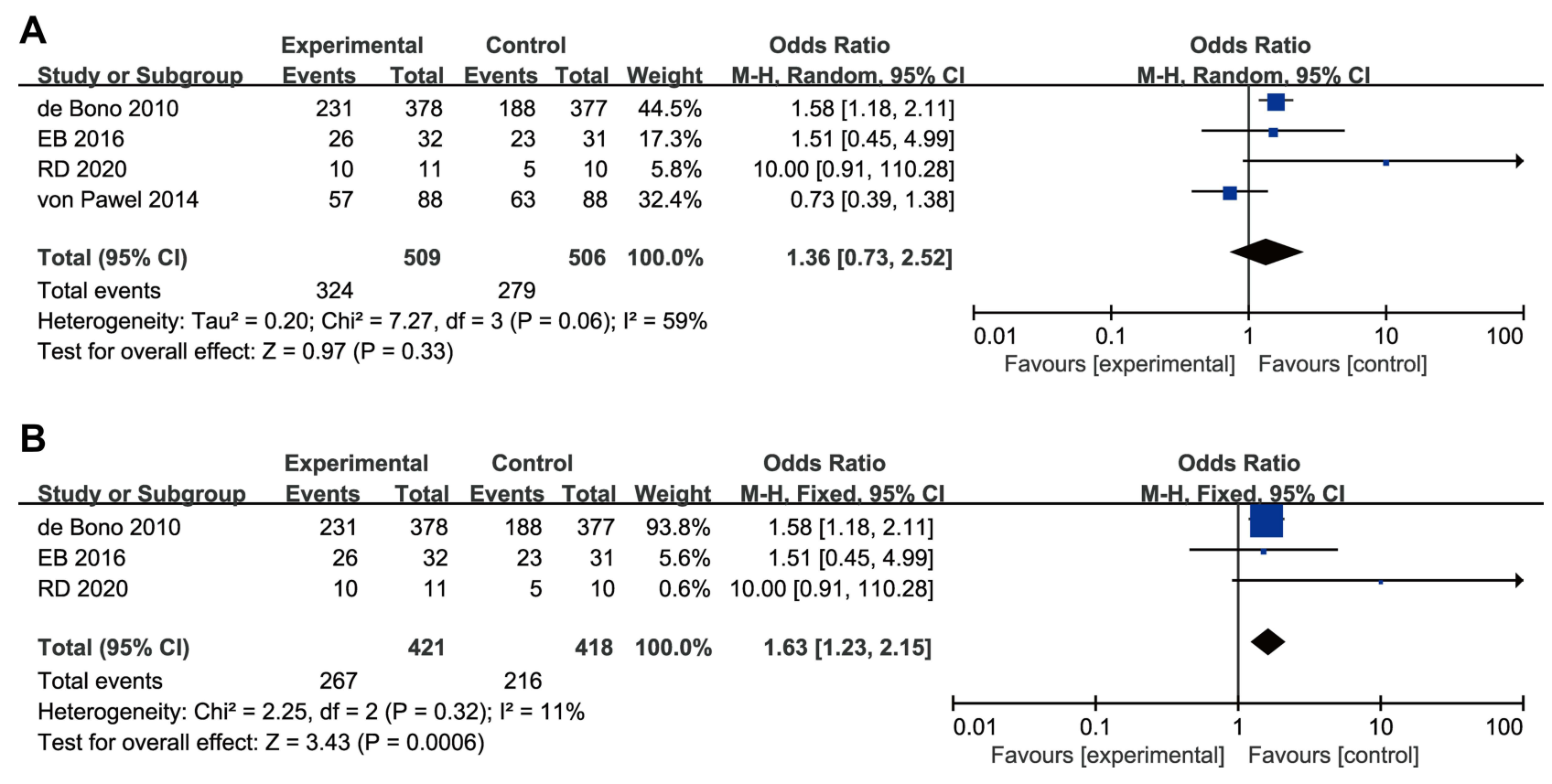

Figure 7 Forest plot diagram of the 0.5 -year survival rate.(A) Forest plot diagram analysed using random-effects model. (B) Forest plot diagram analysed using fixed-effects model. 


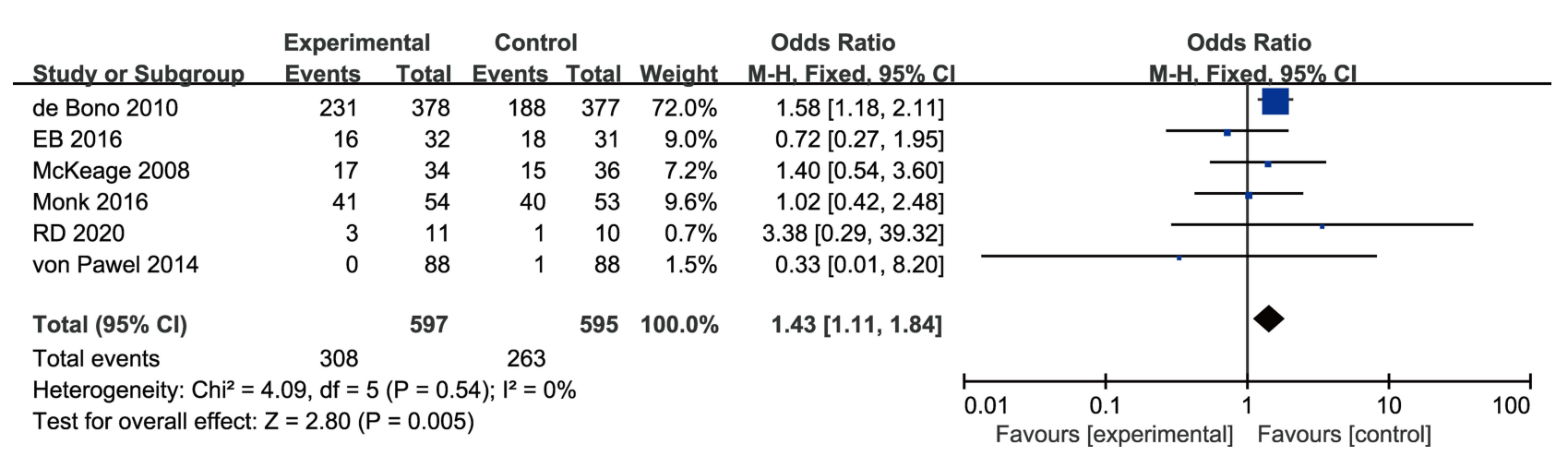

Figure 8 Forest plot diagram of the I-year survival rate.

\section{Discussion}

Cancer is a major public health problem that threatens population health worldwide. The occurrence, progression, invasion, and eventual metastasis and spread of tumors to other parts of the body depends to a large extent on the tumor vascular network. ${ }^{25}$ Tumor vascular targeting drugs provide a novel therapeutic strategy for cancer that is distinct from more commonly used treatments that exert direct cytotoxic effects on tumor cells. ${ }^{26}$ VDAs are a new class of tumor vascular targeting drugs that are currently under clinical study.

A total of 8 publications were included for metaanalysis to compare the efficacy of VDAs, VDAs combined with traditional therapy versus placebo, or placebo combined with traditional therapy, for the treatment of different tumor types. The results from our study indicated that, compared with the control therapies, the experimental VDA-based strategies effectively improved the 0.5year and 1-year survival rates of cancer patients, and increases the 6-month PFS rate. However, there was no significant difference in ORR, DCR, or the 12-month PFS rate between the experimental and control arms.

To the best of our knowledge, this study is the first systematic review and meta-analysis of VDAs or VDAs combined with traditional therapy in the treatment of tumors. However, we did encounter some limitations to our meta-analysis. Firstly, the number of studies included in this analysis was relatively small, and the sample size was also small. Secondly, the coverage of this study may be insufficient in terms of drug types and tumor types. Therefore, it will be necessary to perform more largesample, high-quality randomized controlled clinical trials to provide stricter evidence regarding the therapeutic effects of various VDA-based interventions, which will in turn guide clinical practice regarding the use of these drugs.

\section{Conclusion}

Our meta-analysis showed that the 0.5 -year and 1-year survival rates of tumor vascular disrupting therapy were $64 \%$ and $52 \%$, respectively, effectively prolonging the survival time of tumor patients. With respect to the 6-month PFS rate, tumor vascular disrupting therapy increased by $7 \%$ compared with traditional therapy, and improved the quality of life of tumor patients. However, we did not observe a significant advantage to the use of VDAs in short-term efficacy indexes such as ORR and DCR. Therefore, it is necessary to carry out more large-sample, high-quality clinical trials to confirm the effectiveness of VDAs.

\section{Data Sharing Statement}

No new data were created or analyzed in this study. Data sharing is not applicable to this article.

\section{Acknowledgments}

We thank Professor/Ph.D. Jian $\mathrm{He}$ and Associate Professor/Ph.D. Pan $\mathrm{Wu}$ at National Center for International Research of Bio-targeting Theranostics, Guangxi Medical University, for their valuable contributions.

\section{Funding}

This work was supported by Guangxi Science and Technology Base and Talent Special Project (No. AD17129003), the State Project for Essential Drug Research and Development (No. 2019ZX09301132), the Programs for Changjiang Scholars and Innovative Research Team in University (No. IRT_15R13).

\section{Disclosure}

The authors report no conflicts of interest in this work. 


\section{References}

1. Sung H, Ferlay J, Siegel RL, et al. Global cancer statistics 2020: GLOBOCAN estimates of incidence and mortality worldwide for 36 cancers in 185 countries. CA Cancer J Clin. 2021;71(3):209-249. doi: $10.3322 /$ caac. 21660

2. Miller KD, Nogueira L, Mariotto AB, et al. Cancer treatment and survivorship statistics, 2019. CA Cancer J Clin. 2019;69(5):363-385. doi: $10.3322 /$ caac. 21565

3. Siegel RL, Miller KD, Jemal A. Cancer statistics, 2019. CA Cancer J Clin. 2019;69(1):7-34. doi:10.3322/caac.21551

4. Yoshioka Y, Tsutsumi Y, Nakagawa S, et al. Recent progress on tumor missile therapy and tumor vascular targeting therapy as a new approach. Curr Vasc Pharmacol. 2004;2(3):259-270. doi:10. 2174/1570161043385682

5. Eichhorn ME, Strieth S, Dellian M. Anti-vascular tumor therapy: recent advances, pitfalls and clinical perspectives. Drug Resist Updat. 2004;7(2):125-138. doi:10.1016/j.drup.2004.03.001

6. Roodink I, Leenders WP. Targeted therapies of cancer: angiogenesis inhibition seems not enough. Cancer Lett. 2010;299(1):1-10. doi:10. 1016/j.canlet.2010.09.004

7. Gaya AM, Rustin GJ. Vascular disrupting agents: a new class of drug in cancer therapy. Clin Oncol (R Coll Radiol). 2005;17(4):277-290. doi:10.1016/j.clon.2004.11.011

8. Hasani A, Leighl N. Classification and toxicities of vascular disrupting agents. Clin Lung Cancer. 2011;12(1):18-25. doi:10.3816/CLC. 2011.n.002

9. Hinnen P, Eskens FA. Vascular disrupting agents in clinical development. Br J Cancer. 2007;96(8):1159-1165. doi:10.1038/sj. bjc. 6603694

10. Bieker R, Kessler T, Schwöppe C, et al. Infarction of tumor vessels by NGR-peptide-directed targeting of tissue factor: experimental results and first-in-man experience. Blood. 2009;113(20):50 19-5027. doi:10.1182/blood-2008-04-150318

11. Zhang Z, Shi J, Nice EC, et al. The multifaceted role of flavonoids in cancer therapy: leveraging autophagy with a double-edged sword. Antioxidants (Basel). 2021;10(7):1138. doi:10.3390/antiox10071138

12. Mariotti A, Perotti A, Sessa C, et al. N-cadherin as a therapeutic target in cancer. Expert Opin Investig Drugs. 2007;16(4):451-465. doi:10.1517/13543784.16.4.451

13. Ji YT, Liu YN, Liu ZP. Tubulin colchicine binding site inhibitors as vascular disrupting agents in clinical developments. Curr Med Chem. 2015;22(11):1348-1360. doi:10.2174/0929867322666150114163732

14. Moher D, Liberati A, Tetzlaff J, et al. Preferred reporting items for systematic reviews and meta-analyses: the PRISMA statement. Int J Surg. 2010;8(5):336-341. doi:10.1016/j.ijsu.2010.02.007

15. Cumpston M, Li T, Page MJ, et al. Updated guidance for trusted systematic reviews: a new edition of the cochrane handbook for systematic reviews of interventions. Cochrane Database Syst Rev. 2019;10:D142.
16. Higgins JP, Thompson SG, Deeks JJ, et al. Measuring inconsistency in meta-analyses. $B M J$. 2003;327(7414):557-560. doi:10.1136/bmj.3 27.7414.557

17. Morgan RD, Banerjee S, Hall M, et al. Pazopanib and fosbretabulin in recurrent ovarian cancer (PAZOFOS): a multi-centre, phase $1 \mathrm{~b}$ and open-label, randomised Phase 2 trial. Gynecol Oncol. 2020;156 (3):545-551. doi:10.1016/j.ygyno.2020.01.005

18. Garon EB, Neidhart JD, Gabrail NY, et al. A randomized Phase II trial of the tumor vascular disrupting agent CA4P (fosbretabulin tromethamine) with carboplatin, paclitaxel, and bevacizumab in advanced nonsquamous non-small-cell lung cancer. Onco Targets Ther. 2016;9:7275-7283. doi:10.2147/OTT.S109186

19. Monk BJ, Sill MW, Walker JL, et al. Randomized phase II evaluation of bevacizumab versus bevacizumab plus fosbretabulin in recurrent ovarian, tubal, or peritoneal carcinoma: an NRG Oncology/ Gynecologic Oncology Group Study. J Clin Oncol. 2016;34(19): 2279-2286. doi:10.1200/JCO.2015.65.8153

20. Von Pawel J, Gorbounova V, Reck M, et al. DISRUPT: a randomised phase 2 trial of ombrabulin (AVE8062) plus a taxane-platinum regimen as first-line therapy for metastatic non-small cell lung cancer. Lung Cancer. 2014;85(2):224-229. doi:10.1016/j.lungcan.2014. 05.013

21. Rudin CM, Mauer A, Smakal M, et al. Phase I/II study of pemetrexed with or without ABT751 in advanced or metastatic non-small-cell lung cancer. J Clin Oncol. 2011;29(8):1075-1082. doi:10.1200/JCO. 2010.32.5944

22. Lara PJ, Douillard JY, Nakagawa K, et al. Randomized Phase III placebo-controlled trial of carboplatin and paclitaxel with or without the vascular disrupting agent vadimezan (ASA404) in advanced non-small-cell lung cancer. J Clin Oncol. 2011;29(22):2965-2971. doi:10.1200/JCO.2011.35.0660

23. De Bono JS, Oudard S, Ozguroglu M, et al. Prednisone plus cabazitaxel or mitoxantrone for metastatic castration-resistant prostate cancer progressing after docetaxel treatment: a randomised open-label trial. Lancet. 2010;376(9747):1147-1154. doi:10.1016/S0140-6736 (10)61389-X

24. McKeage MJ, Von Pawel J, Reck M, et al. Randomised phase II study of ASA404 combined with carboplatin and paclitaxel in previously untreated advanced non-small cell lung cancer. $\mathrm{Br} J$ Cancer. 2008;99(12):2006-2012. doi:10.1038/sj.bjc.6604808

25. Gill JH, Rockley KL, De Santis C, et al. Vascular disrupting agents in cancer treatment: cardiovascular toxicity and implications for co-administration with other cancer chemotherapeutics. Pharmacol Ther. 2019;202:18-31. doi:10.1016/j.pharmthera.2019. 06.001

26. $\mathrm{Li} \mathrm{X}, \mathrm{Li} \mathrm{Y}, \mathrm{Lu} \mathrm{W}$, et al. The tumor vessel targeting strategy: a double-edged sword in tumor metastasis. Cells. 2019;8(12):1602. doi:10.3390/cells 8121602
OncoTargets and Therapy

\section{Publish your work in this journal}

OncoTargets and Therapy is an international, peer-reviewed, open access journal focusing on the pathological basis of all cancers, potential targets for therapy and treatment protocols employed to improve the management of cancer patients. The journal also focuses on the impact of management programs and new therapeutic agents and protocols on patient perspectives such as quality of life, adherence and satisfaction. The manuscript management system is completely online and includes a very quick and fair peer-review system, which is all easy to use. Visit http://www.dovepress.com/ testimonials.php to read real quotes from published authors. 